\title{
Research on the course teaching of management statistics based on MOOC teaching
}

\author{
SunHua Mei \\ Finance and Accounting College of AnHui SanLian University, AnHui HeFei, 230601, China \\ About the author: Sunhua Mei(1986-), female, anhui feidong, anhui sanlian college, lecturer, \\ master's degree, financial investment.
}

\begin{abstract}
Key words: MOOC teaching features; Characteristics of the course management statistics; MOOC teaching in management statistics
\end{abstract}

\begin{abstract}
: the course "management statistics" is a compulsory basic course for economics and management majors. It has a wide audience and the main goal of course construction is to improve the teaching quality of the course. With the development of MOOC in full swing, it is worth discussing whether the course of management statistics is suitable for MOOC teaching. This paper analyzes the characteristics of MOOC from the concept, advantages and disadvantages of MOOC. In combination with the characteristics of management statistics, it analyzes the necessity of teaching management statistics combined with MOOC teaching. In this way, it puts forward the teaching Suggestions of management statistics based on MOOC teaching from the aspects of course distribution and theoretical teaching organization.
\end{abstract}

\section{Introduction}

As a compulsory basic course for the major of economic management, management statistics is an applied subject that USES statistical methods to solve management problems and economic problems. With such a developed Internet and computer technology, the introduction of network teaching will greatly improve teaching efficiency and knowledge popularization rate. With the rise of MOOC, the MOOC teaching of management statistics has been proposed. It is worth thinking about how to fully combine the advantages of MOOC teaching to conduct the course teaching of management statistics.

\section{Characteristics of MOOC teaching}

\subsection{The concept of MOOC teaching}

MOOC is Massive Open Online Course, these four English words characterize this education innovation. The first letter M of MOOC corresponds to Massive, mass, and because it's online, tens of thousands of people take a course together that's technically possible. The second letter "O" in MOOC corresponds to "open", "open". The "open" of open education resources means that the resources are freely available. The third letter O of MOOC corresponds to the word online, online. Thanks to the development of the Internet, online education is able to simulate and convey the basic elements of in-school teaching, such as teacher teaching, homework exercises, tests, and peer discussion. The last letter $\mathrm{C}$ in MOOC is the word Course. This is an improvement over open education resource.

\subsection{Advantages of MOOC teaching}

Based on the above characteristics of MOOC, MOOC teaching has the following advantages:

(1) Diversity of tool resources. MOOC courses integrate various social networking tools and various forms of digital resources to form diversified learning tools and rich course resources, providing learners with multiple learning channels. MOOC provides online problem sets, exercises, 
and real-time solutions via network technology. Different from the general online course learners who only accept knowledge unilaterally, MOOC provides learners with corresponding platforms to discuss online exercises and so on. It greatly increases the interest and efficiency of learners to participate in learning.

(2) The course is easy to use. By breaking the limitation of time and space of traditional courses, learners from all over the world can learn the courses of famous universities at home and abroad by relying on the Internet. As mentioned above, MOOC is open course, and the sharing of course resources breaks the barriers of universities, so that learners who do not enter universities or high-level universities for various reasons have the opportunity to learn. At the same time, it also reduces the time constraint for learners and facilitates them to arrange their study time reasonably.

(3) The course has a wide audience. Traditional teaching cannot achieve large-scale course teaching due to the limited time and place, and the teaching is mostly targeted at students. The MOOC model breaks the shackles and allows anyone interested in the course to learn online.

\subsection{Disadvantages of MOOC teaching}

Open, web-based MOOC teaching also has some problems while improving efficiency:

limited exchange between teachers and students. The teaching needs the real-time communication between teachers and students, while the MOOC teaching cannot be like the traditional teaching, and teachers can answer students' questions and doubts at any time. Although MOOC can realize online discussion of learners, online discussion may not be able to accurately solve problems compared with professional solutions of teachers. Even if the teacher can answer online, the large number of learners cannot guarantee that the students have an equal opportunity to receive the teacher's answer, so the learning effect is greatly reduced.

students are at great risk of dropping out. MOOC is open online, and students learn or do not learn voluntarily. At present, MOOC platforms do not have a penalty mechanism for dropping classes. In particular, more theoretical, more difficult courses, not a few dropped out. This lack of supervision cannot guarantee the completion of MOOC teaching.

it is impossible to teach practical courses. Because of its course form, MOOC teaching is suitable for theoretical course teaching, and the practical course teaching which needs students' actual operation cannot be carried out through MOOC. From this point of view, courses with strong practicality cannot be separated from traditional teaching to conduct full MOOC teaching.

Combined with the advantages and disadvantages of MOOC teaching, not all courses are suitable for full MOOC teaching. In the reform of teaching methods, the teaching should be carried out in combination with the nature of courses.

\section{Characteristics of the course management statistics}

Management statistics requires learners to be able to use statistical methods for data analysis and have practical ability to solve problems. The course management statistics has the following characteristics.

(1) Starting from a low base, everyone has a foundation. No matter what status people are in or what job they are engaged in, they will process a large amount of data every day. In the long-term process of dealing with data, even if they have not learned statistics systematically, everyone already has certain statistical knowledge. For example, classification of things, calculation and use of ratios and specific weights, calculation of averages, etc. That is why it is understandable that economic data from business or government statistics are common, without having to be explained to the audience. It can be said that everyone in the society is more or less engaged in statistical work, and therefore has a certain knowledge of statistics, which has laid a certain foundation for students to learn "management statistics" independently.

(2) The course is theoretical and difficult. The course "management statistics" involves a large number of data calculation, which is somewhat difficult. In the curriculum system of economics and management majors in colleges and universities, such courses as probability theory and 
mathematical statistics are the precondition courses of management statistics. Inferential statistics, correlation and regression analysis and variance analysis in statistical methods all require certain probability theory knowledge, which also increases the difficulty for students to learn and understand. The greater difficulty makes students often encounter problems that are difficult to understand and cannot be solved by themselves in the learning process, which requires someone to sort them out and guide them. Teachers play a very important role in the study of management statistics.

(3) Need to combine case teaching. "Management statistics" belongs to applied statistics, which requires students to have the ability to solve economic management problems through course learning, and must highlight how to solve economic management problems with statistical methods in teaching. Based on this, its teaching should be different from the course of "the principle of statistics", instead of only teaching statistical theory, it needs to combine a large number of economic management cases. This requires the teacher to share enough relevant cases in teaching.

(4) It's very practical. Management statistics is a course to collect, collate, analyze and interpret economic management data. Statistical software has obvious advantages in the processing of large amounts of data. Learners should master the application methods of corresponding statistical software in addition to theoretical data processing methods. This requires the course of "management statistics" to offer both theory courses and practice courses, namely computer courses, to teach the use of statistical software such as Excel and SPSS.

To sum up, due to the nature of the course "management statistics", in the absence of offline guidance from teachers, MOOC teaching is completely adopted, so the learning effect will be difficult to guarantee. However, this does not mean that the course of "management statistics" should remain traditional and unreformed. It is necessary to teach the course in combination with MOOC.

\section{The necessity of combining MOOC teaching with management statistics}

(1) There are too many theoretical courses, and MOOC can effectively reduce the proportion of theoretical courses. Due to the strong theoretical nature of the course "management statistics", it is inevitable to spend a large amount of space on theoretical teaching during the process of knowledge transfer, leading to a large proportion of theoretical courses, thus reducing the hours of practical experiment, which is not conducive to the cultivation of students' practical ability. The author obtained the teaching outline of the course of statistics from China national quality course resource network and made statistics on the teaching method and the proportion of class hour. There are 85 excellent courses of statistics on this website, among which 75 courses of course syllabus and course assignment are clearly listed and analyzed. The analysis shows that not all courses are arranged for experimental practice, among which 35 are purely theoretical courses, 38 are "theory + practice" courses, and only 2 are independently set for experimental courses (see table 1). In the course of "theory + practice", the proportion of practical courses in more than $70 \%$ of the syllabus is less than $30 \%$, and the proportion of practical courses is less than $30 \%$ (see table 2 ).

Table 1. Teaching arrangement distribution of 75 syllabi

\begin{tabular}{c|c|c|c}
\hline & The pure theory & $\begin{array}{c}\text { Theory }+ \\
\text { practice class }\end{array}$ & $\begin{array}{c}\text { Set experiment } \\
\text { classes } \\
\text { independently }\end{array}$ \\
\hline $\begin{array}{c}\text { Number of } \\
\text { syllabus }\end{array}$ & 35 & 38 & 2 \\
\hline
\end{tabular}


Table 2 proportion distribution of practice periods in the teaching syllabus of "theory + practice" combined with teaching

\begin{tabular}{c|c|c|c|c}
\hline \multirow{2}{*}{$\begin{array}{c}\text { Specific gravity of } \\
\text { practice course }\end{array}$} & Number & $\begin{array}{c}\text { Upward cumulative } \\
\text { number }\end{array}$ & Proportion & $\begin{array}{c}\text { Cumulative } \\
\text { upweighting }\end{array}$ \\
\cline { 2 - 5 } & 5 & 5 & $13.3 \%$ & $13.3 \%$ \\
\hline Less than $10 \%$ & 11 & 16 & $28.9 \%$ & $42.2 \%$ \\
\hline $10 \%-20 \%$ & 11 & 27 & $28.9 \%$ & $71.1 \%$ \\
\hline $20 \%-30 \%$ & 11 & 38 & $100 \%$ & - \\
\hline More than $30 \%$ & 38 & - & $100 \%$ & - \\
\hline
\end{tabular}

Data source: China national quality course resource network

It can be seen from the above data that, considering the nature of courses, under the premise of limited class hours, there is indeed a situation that the proportion of theoretical courses is too high in traditional teaching. In the teaching mode of MOOC, students can learn theoretical courses through MOOC online teaching video without taking up teaching hours, and teachers can make full use of class time to organize student-oriented classroom teaching activities.

(2) Through MOOC online courses, knowledge review can be conducted at any time. Traditional course teaching is carried out in real time. Even if students take notes in class, they may miss relevant knowledge points. Moreover, the teaching images cannot be left behind. The MOOC online video is to divide the course content into many small videos and store them on the Internet in the form of knowledge points. Secondly, if students forget the knowledge points during the review, they can watch video again to master the knowledge again. The course "management statistics" is very difficult. It is difficult for students to master the course knowledge through only one class teaching by teachers, which requires more reading and review. Therefore, the combination of MOOC teaching will help students to master the course knowledge.

(3) MOOC teaching can realize more integration of teaching resources. Traditional teaching should arrange the teaching content within 45 or 50 minutes, and the limited time requires teachers to make a trade-off between teaching, resulting in many good cases and other teaching resources cannot be taught in class. This can be remedied by combining MOOC teaching. MOOC video online learning requires the student to utilize the extracurricular time to study, do not take up class time, cooperate with relevant teaching video resources (such as related cases and problem sets, etc.) also does not require the students must finish reading, finished in a short period of time, students can learn over a period of time, this means that teachers can be integrated in full, to provide students a more comprehensive teaching resources.

(4) MOOC teaching realizes communication with more people. Through the MOOC platform, learners can discuss with each other. Traditional teaching is often dominated by teacher teaching, with little or no discussion and communication among students. Even if teachers organize the communication between teachers and students and between students, they still cannot leave the scope of the school, which is divorced from the discussion of practice. The MOOC platform is open, and learners on the platform are not only students, but also related practitioners. Through the MOOC platform, students can communicate with relevant practitioners, have a more intuitive understanding of how to use statistical methods to solve economic management problems, and improve students' practical ability.

\section{Combined with the MOOC teaching method of "management statistics"}

To sum up, the course "management statistics" can be carried out on the basis of traditional teaching and combined with MOOC teaching, which not only ensures the guidance of teachers for students' learning, but also provides students with opportunities for independent learning. It not only completed the study of theoretical knowledge, but also improved the proportion of practical experimental courses and enhanced students' practical ability. Specific recommendations are as 
follows:

\subsection{Distribution of school}

Most of the statistics courses have too high proportion of theoretical courses, which leads to too low proportion of practical courses and even pure theoretical teaching. In today's widespread use of computers, various statistical software, students will not be able to analyze the basic statistical software methods; The formulation of statistical investigation program, data collection is also mostly on paper. After the introduction of MOOC teaching, theoretical teaching will not take up too much time. In terms of teaching arrangement, teachers can properly allocate more time in the practice experimental class according to the professional nature, so as to effectively improve students' statistical practice ability.

The practical experiment course needs the student to carry on the concrete organization, the operation, is not easy to realize on the network platform. MOOC is mainly applicable to theoretical course teaching. Therefore, combined with MOOC teaching, it is mainly aimed at the theoretical part of the course "management statistics", and the following recommendations are made for the organization of theoretical courses.

\subsection{Organization of theoretical courses}

(1) Preparation of MOOC teaching resources. The instructor or course group should prepare MOOC resources and upload them in advance. These include MOOC video, problem sets, cases, etc. Video should be spread around knowledge point, each video should not be too long, 10-15 minutes can. At the same time, we should provide corresponding exercises and cases for students to practice and learn online. The construction of MOOC courses is not achieved overnight, and teachers need to keep learning and improving in the early stage. When the relevant resources are ready, the MOOC can be combined to carry out teaching activities in the course of management statistics.

(2) Students study before class, and teachers solve puzzles in class. Before the lecture, the teacher arranges students to learn the knowledge points to be taught online in advance. After learning, students can do online answering exercises and fully communicate with other learners, including classmates and relevant practitioners. In this process, teachers can master the learning situation of students through two points. Second, teachers can monitor students' answers through computer terminals, so as to understand students' knowledge grasp. Through the above two points, the teacher can conclude and summarize, and focus on the explanation of the key and difficult points in class instead of the professor of all knowledge. It will greatly improve the efficiency of teaching.

(3) Organize students' discussion and strengthen students' initiative in learning. In the course of teaching, the teacher plays a supporting role with students as the leading role. Students can be divided into groups of 5-6. Each group is assigned a topic. Each group is prepared to explain the content in the class according to the learning situation and discuss with other students about problems. Teachers should be involved in solving doubts. In this way, students' learning and participation will be enhanced.

Management statistics is a course integrating theory and practice, which cannot be completely divorced from traditional teaching. Combined with MOOC teaching, it can effectively improve the teaching efficiency and optimize the teaching effect. It can be popularized in teaching.

\section{Acknowledgement}

Fund project: provincial quality project of education department of anhui province: comprehensive reform pilot of financial management major (2016ZY044); Anhui sanlian university, university-level quality engineering: characteristic major of financial management (12zlgc024)

\section{References:}

[1] xin yongtao. Preliminary study on the teaching reform in universities from the perspective of 
MOOC [J]. Teacher, 2014, 04:24-27.

[2] qichao. Opportunities and challenges faced by college teachers in the context of MOOC [J]. Occupational technology, 2015, 09: 55-57.

[3] ge mutian. Research on the construction of learning resources under the environment of "Internet + " [J]. Journal of nanjing radio and television university, 2017, 12: 88-91.

[4] an zeman. A preliminary study on the existing problems and reform points in college statistics teaching [J]. Journal of jilin radio and television university, 2017, 05: 137-138.

[5] zhao lei. Study on the essential characteristics and analytical framework of MOOC innovation diffusion [J]. China remote education, 2018, 03: 45-51. 